\title{
Programas Oficiais para Formação dos Professores da Educação Básica
}

\author{
Maria Teresa Leitão de Melo *
}

RESUMO: O artigo analisa a formação dos professores da educação básica destacando dois eventos ocorridos na última década: a Conferência Mundial de Educação para Todos e a Lei de Diretrizes e Bases da Educação Nacional. Avalia os desdobramentos advindos dos referidos eventos e a sua influência nos programas oficiais de formação, criticando a tônica no aperfeiçoamento em serviço restrito a algumas áreas, de conteúdo fragmentado, aligeirado, sem repercussão na carreira docente. Contextualiza a formação no âmbito das políticas de valorização do magistério, categorizando-a como direito do professor. Lança o desafio de construir o perfil e a identidade do profissional da educação, considerando os atores que atuam na escola e têm vínculo com o trabalho educativo: professores e funcionários da educação, portadores do direito a uma formação includente e de qualidade social.

Palavras-chave: Formação de professores, educação básica, programas oficiais, trabalho educativo

\section{Um breve olhar sobre aúltima década}

A partir da Conferência Mundial de Educação para Todos, realizada em Jomtien, Tailândia, em 1990 e, mais recentemente, da aprovação

\footnotetext{
* Secretária de Assuntos Educacionais da Confederação Nacional dos Trabalhadores em Educação (CNTE) e Presidente do Sindicato dos Trabalhadores em Educação de Pernambuco (Sintepe).Email: rfmelo@elogica.com.br
} 
da Lei de Diretrizes e Bases da Educação Nacional, lei $\mathrm{n}^{\circ}$ 9394, em 1996, a formação de professores é tema obrigatório nos debates educacionais, considerando os novos contornos pontuados por esses dois eventos.

No primeiro, por se constituir em elemento importante do processo de universalização da educação proposto pelos organismos internacionais dele promotores. Aqui no Brasil, nos desdobramentos que sucederam à Conferência, a formação dos professores volta a ser destacada. Inicialmente, no Acordo Nacional e no Pacto pela Valorização do Magistério e Qualidade da Educação, ambos documentossíntese das intenções e prioridades do Plano Decenal de Educação para Todos, consenso possível firmado (e posteriormente ignorado pelo governo atual) entre o poder público, as organizações governamentais e as entidades acadêmicas e sindicais do movimento de educadores brasileiros. Depois a formação reaparece nos estudos do planejamento estratégico realizados pelo Fórum Permanente pela Valorização do Magistério e Qualidade da Educação, responsável pelos encaminhamentos do Plano Decenal. Desta feita, contextualizada como um dos "nós críticos" da educação brasileira dentro do problema da desvalorização do magistério.

Foram muitos os debates e várias as expectativas que se revelaram em torno do tema. Infelizmente, o descumprimento do Acordo Nacional, em 1995, por parte do presidente da República, fez abortar uma série de medidas que consolidariam o acúmulo do debate do Fórum Permanente, além de abrir espaço para outro panorama educacional rumo à Emenda Constitucional $\mathrm{n}^{\circ} 14 \mathrm{e}$, em seguida, à nova LDB.

Em que pesem todas as limitações e o próprio significado político do Acordo Nacional e do Pacto pela Valorização do Magistério, assumidos por signatários tão díspares em sua concepção e defesa de projeto social, é inegável a contribuição ao debate e a problematização apontada para a formação dos professores advindas desses documentos.

Na LDB - lei no 9394/96 -, o segundo evento atual apontado por nós como instigador desse temário, até chegar à formulação final, os percalços foram muitos e tortuosos foram os caminhos.

A formação dos professores é tratada no título "Dos profissionais da educação", uma das partes mais reduzidas em seu conteúdo quando da tramitação do projeto de lei entre a Câmara de Deputados e o Senado Nacional. Em apenas seis artigos, a lei pretende definir os fundamentos, de- 
limitar os níveis e o locus da formação e relacioná-la aos requisitos da valorização do magistério. O resultado de tamanho "enxugamento" é a ausência da conceituação dos profissionais da educação, referenciados no texto da lei com base nas exigências para sua formação, além de algumas contradições, que analisaremos mais adiante, no tocante aos próprios cursos e espaços de formação.

Atualmente, em tempos de regulamentação da LDB, aliada às exigências do Banco Mundial para o desenvolvimento e a manutenção da educação brasileira, a temática da formação dos professores ganha novos destaques. Um dos requerimentos básicos, alertado pelo movimento dos trabalhadores em educação, é o de inserir as políticas e os programas de formação no processo global da valorização profissional.

\section{A dimensão social da formação profissional}

Entender a formação na perspectiva social é entendê-la e defendê-la como um direito do professor. É superar o estágio de iniciativas individuais para aperfeiçoamento próprio e colocá-la no rol das políticas públicas para a educação.

Pensando assim, a formação compõe com a carreira e a jornada de trabalho, que por sua vez devem estar vinculadas à remuneração, elementos indispensáveis à formulação e à implementação de uma política de valorização profissional que contribua tanto para o resgate das competências profissionais dos educadores, como para a (re)construção da escola pública de qualidade.

É, portanto, um processo inicial e continuado que deve dar respostas aos desafios do cotidiano escolar, da contemporaneidade e do avanço tecnológico. O professor é um dos profissionais que mais necessidade têm de se manter atualizados, aliando à tarefa de ensinar a tarefa de estudar. Transformar essa necessidade em direito é fundamental para o alcance da sua valorização profissional e desempenho em patamares de competência exigidos pela sua própria função social.

Recente pesquisa realizada em parceria pela Confederação Nacional dos Trabalhadores em Educação (CNTE) e pelo Laboratório de Psicologia do Trabalho, da Universidade de Brasília, sobre as condições de trabalho e a saúde dos trabalhadores em educação, revelou indicadores no mínimo 
perturbadores acerca da prática educativa relacionada a apropriação/expropriação de competências. O novo perfil do aluno, como sujeito social que leva para a escola novos padrões de comportamento; a competição com outros agentes educativos/informativos fora da escola; a celeridade do avanço tecnológico, nem sempre ao alcance de todos, são fatores que interferem na relação do professor com o conhecimento, objeto primeiro do seu trabalho, que precisa ser entendido como processo, portanto matéria ao mesmo tempo cumulativa e provisória.

Os dados da pesquisa revelam que a auto-estima do professor, já tão comprometida pela acentuada desvalorização salarial, sofre impactos que ganham dimensão de verdadeira síndrome - a síndrome da desistência, conhecida como burnout - diante da impotência em realizar sua tarefa. Mesmo sabendo, teoricamente, como executá-la, faltam-lhe elementos essenciais à segurança da prática pedagógica.

Nesse sentido, articulando os dados da pesquisa à formação na perspectiva do direito, cabe a reflexão de Vieira (1999), ao elencar alguns fatores a serem considerados como desafios nessa realidade: a angústia do professor de "não saber de tudo", a perda gradativa da capacidade de formulação, a formação compartimentada e as contradições da identidade social.

Uma política de formação profissional direcionada para essa realidade precisa, pois, nascer no chão da escola para voltar-se a ele, atentando para as múltiplas dimensões em sua formulação e implementação, capazes de construir competências coletivas e definir a intencionalidade da prática educativa.

É evidente que não podemos prescindir da reflexão sobre a própria prática como elemento constitutivo das políticas de formação, principalmente porque essa leitura crítica desvelará espaços de tensão a serem trabalhados. Porém, é necessário que a reflexão, ao tempo em que contribua para superação de limites e construção de possibilidades, esteja fundamentada em sólidas bases teóricas e epistemológicas, assim como as defende Frigotto (1996):

as dimensões técnica e didática no processo de ensino, para serem efetivas, implicam necessariamente a dimensão teórica e epistemológica e que, sem estas, aquelas podem se constituir em bloqueadores de processos de conhecimentos previamente construídos pelo aluno. (pp 95-96) 
Dessa forma estará sendo concebida a autonomia intelectual do professor, necessária para o redimensionamento da sua prática, para a luta e a resistência em defesa da qualidade e do respeito a seu exercício profissional.

\section{Os programas oficiais de formação: Legislação e políticas de governo}

A intenção de destacar, nos programas oficiais de formação, a relação entre as políticas de governo e a nova legislação educacional, especialmente a LDB e o Projeto de Plano Nacional de Educação, reside na necessidade que vislumbramos de tecer nossa análise tendo como eixo as contradições e ambigüidades que se evidenciam nos encaminhamentos do Ministério da Educação.

A primeira questão diz respeito à composição da educação nacional, disposta no artigo 21 da lei 9394/96, em apenas dois níveis: a educação básica e a educação superior. O próprio vocábulo "básica" por si só nos enseja uma concepção: "que serve de base, basilar, fundamental, essencial" (Buarque de Holanda 1993). Seria, pois, o nível da educação indispensável ao atendimento do que dispõe a própria LDB no seu artigo 22: "A educação básica tem por finalidades desenvolver o educando, assegurar-lhe a formação comum indispensável para o exercício da cidadania e fornecer-lhe meios para progredir no trabalho e em estudos posteriores" (Brasil 1996).

Os programas oficiais de formação para professores da educação básica haveriam, pois, de considerar essa concepção, para manter a unidade do nível de educação e resguardar o perfil e a identidade do professor.

Porém, a despeito da "letra da lei", as políticas globais de governo fragmentam a educação básica em ensino médio e ensino fundamental, subdividindo este último em primeiro ciclo ou fase inicial ( $1^{1^{a}}$ a $4^{\underline{a}}$ série) e segundo ciclo ou fase final ( $5^{\mathrm{a}}$ a $8^{\mathrm{a}}$ série), deixando as outras modalidades totalmente excluídas das prioridades dos programas de governo educação infantil, educação especial, educação de jovens e adultos.

Essa diretriz é bastante visível nas políticas de financiamento e na regulamentação promovida pela lei 9424/96, que dispõe sobre o Fundef - Fundo de Manutenção e Desenvolvimento do Ensino Fundamental, bem como nas políticas de municipalização do ensino, voltadas principalmente para as quatro primeiras séries do ensino fundamental. 
Fratura-se a educação básica, fratura-se o financiamento, fratura-se a organização dos sistemas... Que unidade restará para os programas de formação e para a identidade profissional do professor?

A política oficial de formação, implementada pelo Ministério da Educação, não responde a essa indagação. Ou melhor, responde ao afirmar na formulação e nos encaminhamentos de seus programas a mesma lógica fragmentada com que trata a educação básica.

Voltando à LDB, a esse respeito, é importante destacar, dentre as atribuições que ela concede ao professor (artigo 13, I), um nível mais rigoroso de formulação e responsabilidade, elencando, ao lado das incumbências já consideradas rotineiras, a participação na elaboração da proposta pedagógica da escola, espaço que pode vir a ser estimulador da conquista de crescentes estágios de autonomia escolar e de democratização da gestão.

Ora, esse salutar nível de exigência para uma prática pedagógica que ultrapasse a visão puramente instrumental, resumida à transmissão de conhecimentos e ao tarefismo de "dar aulas", precisa influenciar os programas oficiais de formação, a ser considerada em toda sua complexidade. Do contrário, a sensação que aos poucos vai se consolidando é de que novas e mais complexas atribuições são delegadas aos professores, sem que sejam acompanhadas das condições objetivas de realizá-las. Se, por um lado, esse grau de responsabilidade fortalece e revigora a função social do magistério e da própria escola, por outro, se não for muito bem articulado, poderá gerar fortes e perigosos sentimentos de frustração e de impotência.

Nesse aspecto, convém lembrar uma das contradições que estamos vivendo na conjuntura educacional: no momento em que $o$ ato educativo se torna mais complexo e as exigências de escolarização mais presentes, ocorre um certo empobrecimento cultural e reduzem-se as metas e os objetivos da formação docente, evidenciando grande descompasso entre as políticas de formação e os objetivos proclamados de melhorar a qualidade da educação pública.

Analisemos essa afirmação considerando três aspectos: primeiro, os espaços de formação previstos na LDB; segundo, a categorização de professor ensejada pelos programas de formação e, terceiro, o modo operacional pelo qual as políticas e os programas de formação vêm se difundindo nos sistemas de ensino.

Ao analisarmos o Título VI da LDB - Dos profissionais da educação -, reconhecemos nele a síntese das normas sobre fundamentos, conceituação, 
níveis e espaços de formação. A mão do legislador cuidou, aparentemente, de dotar a lei de um leque multifacetado de opções, introduzindo algumas novidades, como os Institutos Superiores de Educação, e resgatando antigas imagens como as Escolas Normais. Não conseguiu se livrar de algumas ambigüidades e contradições oriundas, talvez, do violento processo de "enxugamento" imposto a esse título da lei, quando da tramitação do projeto entre a Câmara Federal e o Senado Nacional. Dessa forma registra-se na lei (artigo 62), em grau de paridade, que a formação do docente far-se-á em nível superior, em cursos de licenciatura plena, em universidades e institutos superiores de formação, sem qualquer prioridade para as licenciaturas que, historicamente, se diferenciam dos demais cursos de graduação, exatamente pela especificidade da formação para a docência.

A aplicabilidade da leitura do artigo nas políticas de governo concretiza-se com o esvaziamento das licenciaturas e a ênfase em "transformar" graduados em professores, da noite para o dia, mediante os cursos de complementação pedagógica. Paralelamente o Governo investe na regulamentação dos Institutos Superiores de Educação, a despeito de toda polêmica gerada no próprio Conselho Nacional de Educação e das argumentações e proposições de entidades representativas dos educadores.

Outro espaço de formação citado no referido artigo 62 é o da modalidade normal, um nível médio, apontado por alguns como contraditório ao parágrafo $4^{\circ}$ do artigo 87 , que exige, até o final da Década da Educação (ano 2006), que todos os professores sejam habilitados em nível superior ou formados por treinamentos em serviço. Mais uma vez omite-se a exigência da licenciatura plena.

Esse leque de opções, ou quem sabe a intencionalidade que ele encerra ou ainda os objetivos e as metas dos programas de formação, tem possibilitado que a consecução das políticas de governo seja marcada pela fragmentação e pelo aligeiramento, não apenas no aspecto organizativo e temporal, mas também no tocante ao aprofundamento de conteúdos e à apropriação de competências.

O segundo aspecto diz respeito à concepção de professor que nasce dessa política de formação. Não mais o professor que identifica na necessidade de formação especializada os pré-requisitos e os critérios para construir o seu perfil profissional. Não mais o professor que se dedica à formação própria para a docência para afirmar/reafirmar a sua própria identidade. Agora pode ser professor aquele portador de diploma de curso superior que "queira se dedicar à educação básica" (artigo 63, I da LDB). 
É um cheiro de diletantismo no ar, quando os ares da modernidade pretendem maior rigor nos critérios de profissionalização. E por que não para os professores?

Por fim, como síntese dos aspectos anteriores, o terceiro aspecto: de como os programas de formação estão se difundindo nos sistemas de ensino.

Antes de mais nada, há de se convir que o Ministério da Educação cumpre, com muita aplicação, o seu papel regulador das políticas educacionais. Embora atropele constantemente o debate e secundarize a interlocução com a sociedade, o MEC apresenta uma significativa linha de produção em termos de projetos, documentos e programas. Em alguns momentos, uma avalanche de medidas chega aos sistemas sem que as escolas tenham oportunidade de se pronunciar se desejam, se precisam, se entendem, se aprovam as determinações. Muitas vezes a propaganda chega primeiro, com a informação televisiva maquiada com o devido capricho para acompanhar um astro ou uma estrela de televisão.

Nos programas de formação não tem sido diferente. Os dados do próprio MEC indicam a premência em investir na formação dos professores da educação básica. O problema é como e para quê. Nesse assunto o Ministério é extremamente pragmático e, ao mesmo tempo, inteiramente submisso aos ditames do Banco Mundial. Dessa maneira, as áreas prioritárias nos programas de formação atendem às políticas traçadas pelo Banco Mundial, na forma e no conteúdo.

De um lado, habilitar todos os professores leigos, que são muitos ainda, principalmente nas regiões Norte, Nordeste e Centro-Oeste. É a resposta ao insumo, vexatório do ponto de vista da qualidade e cruel do ponto de vista da profissionalização. Por outro lado, o investimento feito na política de formação prioriza duas dimensões: o desenvolvimento profissional dos docentes em exercício, aqui incluído o acesso a níveis superiores, e os programas de aperfeiçoamento em serviço.

Claramente, o aperfeiçoamento em serviço ocupa maiores espaços nos programas de formação. Entretanto apresentam limitações graves. Uma delas encontra-se nos dispositivos da Resolução $n^{\circ}$ 03/97, do Conselho Nacional de Educação, que fixa as Diretrizes para os Novos Planos de Carreira e Remuneração do Magistério Público. No parágrafo único, do artigo $5^{\circ}$, a resolução explicita três critérios a serem considerados/priorizados nos programas de capacitação em serviço: as áreas curriculares carentes de profes- 
sores, os professores com mais tempo de exercício a cumprir nos sistemas e a utilização de metodologias que incluam recursos de educação a distância.

Os critérios são, pois, seletivos, excluindo uma parcela dos professores dos programas de aperfeiçoamento, além de evidenciarem uma tônica de treinamento em serviço, em detrimento de uma política de formação includente, reflexiva e crítica. A perspectiva da qualidade, compreendida como direito ao saber, à ciência e à tecnologia, é prejudicada.

A esse respeito há de se destacar, também, uma certa confusão que paira sobre os programas de formação ora em vigor: capacitação e formação docentes teriam o mesmo significado?

Parece haver uma redução na concepção de formação docente, de modo a colocá-la tão-somente no âmbito da capacitação. Ou seja, os instrumentos, mecanismos e conteúdos escolhidos pretendem se voltar, fragmentariamente, para um dos aspectos da formação docente, que é como podemos considerar a capacitação em serviço. Esse excesso de pragmatismo tem contribuído para que se confunda o espaço e as finalidades de cada um desses elementos e, mais que isso, tem restringido o direito a uma política de formação ampla, permanente e contemporânea, em troca de aligeirados e modulares momentos de aperfeiçoamento.

Destaca-se, ainda, que essa concepção de formação continuada, por não favorecer o acesso a níveis superiores de graduação, não tem qualquer repercussão na carreira do professor, não se situando, pois, como componente das políticas de valorização do magistério.

\section{Seria o Plano Nacional de Educação uma alternativa?}

No contexto desse debate, embora com dez anos de atraso, a disputa de projetos que envolve a tramitação do Plano Nacional de Educação (PNE) é um fato significativo para (re)colocarmos algumas das questões em movimento nos programas de formação para os professores da educação básica.

Um dos grandes problemas do projeto de Plano Nacional de Educação, elaborado pelo MEC, é que ele reforça as ambigüidades contidas na LDB em relação aos espaços de formação e, conseqüentemente, ao perfil do professor. Vai mais longe ainda - e, portanto, aproxima-se mais das políticas de governo - nas proposições de formação para cada um dos 
níveis de ensino, fragmentando a educação básica e introduzindo novas categorias profissionais para realizar tarefas específicas do professor. É o caso, por exemplo, do agente educativo para atuar em creches e pré-escola, cuja exigência de formação não passa do Ensino Fundamental e Médio. Considerando que a educação infantil é parte integrante da educação básica, é inadmissível que não seja entregue aos professores. Do contrário, estaremos rompendo com a visão de educação escolar de zero a seis anos que ela afirma, ao ser incluída na educação básica, tratando-a como se fosse a extensão da casa e da família. A educação infantil tem, por força da própria organização dos níveis de ensino, uma tarefa educativa própria, e por isso necessita ser entregue a professores habilitados.

Para a atuação na área da educação especial, o PNE/MEC recomenda a utilização prioritária da educação a distância como metodologia. Longe de nós abdicar das vantagens e dos benefícios que podemos usufruir com o avanço tecnológico, que deve, sim, ser usado em caráter educacional. O que nos assusta, nesta e em outras áreas da formação, é o uso exclusivo desse recurso, reduzindo possibilidades de avanço já experimentadas pelas licenciaturas e pelos cursos de magistério e quebrando a magia do ambiente escolar e da interação pedagógica.

Em relação às outras modalidades de formação, o PNE/MEC segue a mesma lógica da LDB, particularmente nas exigências de formação de nível médio ou superior.

Entretanto, há dois sinais bem nítidos do significado que o PNE/MEC possa vir a ter para as políticas de formação caso seja aprovado como foi proposto e que avançam, negativamente, na concepção presente na LDB. Um deles diz respeito à desregulamentação dos processos de formação profissional, os quais perdem a escola como locus privilegiado de troca de aprendizagens e de enriquecimento cultural, secundarizando portanto a escolarização como direito do professor. A outra consideração retorna aos critérios que defendemos como basilares para a valorização profissional: o PNE/MEC não articula formação, carreira e jornada como componentes de um mesmo campo de perfil profissionalizante do professor.

Os espaços de disputa por um processo de formação includente, de qualidade e valorativo estão postos. Tramita no Congresso Nacional um outro PNE gestado no chão da escola, legitimado em dois Congressos de Educação (os Coneds) e apoiado por amplos setores sociais. Apostar nessa disputa, alargando nossos espaços de participação, é tarefa urgente da qual não podemos nos furtar. 


\section{Programas de formação e organização curricular}

Há uma tônica presente nos documentos e nas propostas de formação do MEC que é a relação com a organização curricular.

Recente documento produzido pela Secretaria de Ensino Fundamental para professores de $1^{\text {a }}$ a $4^{\text {a }}$ série assume, explicitamente, a total dependência aos Parâmetros Curriculares Nacionais (PCNs), que devem, sim, ser objeto dos programas de formação, mas não funcionar como matriz do processo formativo. Ao submeter a política de formação aos PCNs, para a eles se adequar, o MEC mantém a política de restrição e fragmentação já denunciada em nossa reflexão. Ademais, revela outra intenção, que é alçar os parâmetros curriculares à posição de diretrizes com caráter mandatório. À escola, ao professor só restaria segui-los.

A própria concepção de apropriação de competências profissionais e de profissionalização do professor adquire características muito estreitas, resumidas ao desenvolvimento profissional permanente e a uma polêmica avaliação do desempenho, com fins de progressão na carreira.

Confina-se a formação ao âmbito dos PCNs, cuja abrangência não ultrapassa a $4^{\text {a }}$ série e na espera de que os PCNs de $5^{\text {a }}$ a $8^{\underline{a}}$ série obtenham o mesmo grau de popularidade, aguarda-se o momento mais propício para a tão necessária e desejada articulação.

Outro enfoque que merece ser tratado são as alterações curriculares dos níveis e das modalidades de ensino, em curso no Conselho Nacional de Educação (CNE), trazendo mudanças significativas na organização dos tempos e espaços escolares. Do CNE já emanaram as diretrizes curriculares para o ensino fundamental; para o ensino médio; para a educação infantil; para a educação indígena, e, está em debate, para a educação profissional.

Além dessas, as duas resoluções específicas da formação de professores - referentes à modalidade normal em nível médio e aos Institutos Superiores de Educação - certamente aguçarão o debate sobre a legislação e as políticas de governo. Não são sem motivo as preocupações das entidades de classe e de vários acadêmicos sobre o destino das licenciaturas e do curso de pedagogia.

Algumas dessas diretrizes são mais profundas nas transformações a que se propõem, tanto na operacionalização quanto na própria concepção de currículo. A ousadia em propor novos referenciais para as esco- 
las, muitos deles promotores de uma saudável tensão sobre conservadoras formas de ensinar/aprender, não tem sido suficiente ainda para intervir nos programas de formação e estabelecer os mecanismos de inter-relação. Há pressa em dar um novo perfil às escolas, com risco até de se ficar nas aparências, mas se secundariza o tratamento global urgente e necessário a essas modificações, incluída nele a política de formação dos professores, além, é claro, do aumento de investimentos e da melhoria da infra-estrutura, material e didática, das escolas públicas.

O Conselho Nacional de Educação tem sido enfático, nos relatórios que subsidiam suas resoluções curriculares, em explicitar, como fundamentos norteadores das novas propostas pedagógicas, os princípios éticos (da autonomia, da responsabilidade, da solidariedade e do respeito ao bem comum), os princípios políticos (dos direitos e deveres de cidadania, do exercício da criticidade e do respeito à ordem democrática), os princípios estéticos (da sensibilidade, da criatividade, da ludicidade, da qualidade e da diversidade de manifestações artísticas e culturais).

Ressalta ainda o CNE que as propostas pedagógicas, fruto das modificações curriculares, devem promover e explicitar o reconhecimento da identidade do aluno, do professor e de outros profissionais que atuam na escola, como componentes da construção da identidade da própria escola.

Assim sendo, abre-se mais uma exigência nos programas de formação: tratar as questões pertinentes à organização curricular na perspectiva de considerar o professor como sujeito do seu próprio processo de formação e como construtor do projeto político pedagógico da escola, capaz de intervir, em conjunto com outros atores, na implementação dessas diretrizes curriculares. O contrário é tratá-lo como mero executor de políticas governamentais.

Se é verdade, e acreditamos sê-lo, que a natureza dessas mudanças curriculares ocorre em meio a um processo ao mesmo tempo de ruptura e de transição, urge dimensionar os programas de formação para o atendimento dessa realidade.

Afinal, é na vivência curricular e numa concepção mais abrangente de currículo que se cruzam o direito de aprender e o direito de ensinar e que se constrói o retrato da escola, com suas cores e suas dores e suas alternativas de conquista da qualidade. 


\section{Horizonte e desafios para \\ uma política de formação includente e de qualidade}

Hoje, novas demandas estão postas para a escola e, portanto, para os profissionais que nela atuam. Um dos desafios atuais diz respeito, exatamente, à definição do perfil e da identidade desses profissionais.

A concepção construída no interior da Confederação Nacional dos Trabalhadores em Educação (CNTE) e levada ao debate público em vários fóruns estabelece um novo conceito de profissional da educação, que é ampliado para incluir os demais agentes educativos que atuam na escola, além do professor.

Para nós, a identidade é constituída com base no vínculo com o trabalho educativo, o que nos remeterá a exigências de formação profissional específica, na perspectiva de consolidar essa identidade e qualificar o próprio trabalho educativo.

Essa reflexão materializou-se na formulação das áreas de atuação e carreira desse segmento, a quem denominamos funcionários da educação, e em propostas de formação e profissionalização, já praticadas em Mato Grosso e no Distrito Federal. São quatro as áreas de profissionalização: técnico em administração escolar, técnico em alimentação escolar, técnico em manutenção e infra-estrutura escolar e técnico em multimeios didáticos.

A essência do debate é alargar o horizonte da conceituação de profissional de educação, considerando a complexidade do ato educativo, as relações que podem ser estabelecidas a partir desse novo conceito e o enriquecimento que dele poderá vir para a ampliação e o fortalecimento da função da escola.

Diferentemente de propostas oficiais que pretendem entregar tarefas educativas a qualquer profissional não habilitado, a nossa tese está diretamente ligada a uma formação específica para atuar na área da educação. As experiências nos têm mostrado a grande contribuição que essa concepção traz para a valorização profissional e a qualidade da educação.

Temos conhecimento, inclusive, da ampliação desse debate para outros setores profissionais que têm sua prática vinculada à escola e à educação. É o caso dos psicólogos escolares que, categorizados como tal, 
discutem e reivindicam ser considerados como profissionais da educação.

Essa gama de proposições precisa ser tematizada nas políticas de formação, considerando os próprios desafios postos para a educação pública, cuja oferta tem crescido na última década, mas precisa ser acompanhada da melhoria do padrão de qualidade.

Refletindo sobre todo esse contexto, a CNTE elaborou as seguintes proposições a serem incorporadas ao PNE da sociedade brasileira:

1. orientar a formação dos trabalhadores em educação nos princípios filosóficos da liberdade de expressão e de pensamento, nos ideais de coletividade e solidariedade humana, resgatando o sujeito sociopolítico capaz de intervir no processo de construção da história;

2. articular agências formadoras e empregadoras para a elaboração de políticas e programas de formação do trabalhador em educação, sintonizados com as novas tecnologias, contando com a participação de associações profissionais e organizações sindicais;

3. criar mecanismos para a escolarização dos funcionários da educação, para que todos obtenham o grau de escolaridade em nível de ensino médio;

4. ampliar convênios com as universidades públicas para a realização de cursos de formação continuada;

5. garantir recursos para projetos de formação profissional na lei orçamentária em âmbito estadual e municipal;

6. profissionalizar todos os trabalhadores que atuam na educação pública em um prazo de 10 anos.

A despeito de tantas dificuldades analisadas, temos convicção de que os elementos denunciadores da disputa de projetos, presentes na política de formação, constituem rico e estimulante espaço para manter viva a nossa esperança de construir/conquistar melhores dias para a escola pública e seus profissionais e renovam o nosso direito de sonhar com uma educação democrática e de qualidade social. 
Official programs for the formation of basic education teachers.

ABSTRACT: The article analyses the formation of basic education teachers highlighting two events that took place last decade: The World Conference of Education for All and The Directive and Basis Law of the National Education. It evaluates the unrolling coming from these events already mentioned and their influence in the official programs of formation, criticising the tonic in the improvement in restricted service to some areas, having a fragmented content, hastening, with no repercussion in the ambit of valorization policies of teachership, categorizing it as the right of the teacher. It originates the challenge to build up the profile and the identity of the education professional, considering them the actors that act on school and have a link with educative work: teachers and workers of education, having the right to an including formation and with social quality.

\section{Bibliografia}

BRASIL/CEB/CNE. Diretrizes Curriculares Nacionais para a Educação Indígena.

BRASIL/MEC/CNE. Resolução $\mathrm{n}^{\circ}$ 03/97 - fixa as Diretrizes para o Novo Plano de Carreira e Remuneração do Magistério Público.

. Resolução CEB no 02/98. Diretrizes Nacionais para o Ensino Fundamental.

. Resolução CEB no 03/98. Diretrizes Nacionais para o Ensino Médio.

. Resolução CEB no 01/99. Diretrizes Nacional para o Ensino Infantil. CNE/MEC.

Resolução CEB nํ03/99. Diretrizes Curriculares Nacionais para a Formação de Professores na Modalidade Normal em Nível Médio.

BRASIL/MEC/SEF. Referenciais Nacionais para Formação de Professores do Ensino Fundamental.

BRASIL/PR. Lei no 9.394, de 20/12/1996. Estabelece as diretrizes e bases da educação nacional. Diário Oficial da União. Brasília: Gráfica do Senado, ano CXXXIV, nl. 248, 23/12/96, pp. 27833-27841. 
BUARQUE DE HOLANDA, Aurélio. Novo dicionário Aurélio da língua portuguesa. Rio de Janeiro: Nova Fronteira, 1993.

FRIGOTTO, Gaudêncio. "A formação e a profissionalização do educador: Novos caminhos". In: GENTILI, P \& T.T. (orgs.). Escola S.A. Quem ganha e quem perde no mercado educacional do neoliberalismo. Petrópolis; Brasília: Vozes/CNTE1996.

VIEIRA, Juçara Dutra. "Formação e carreira". Cadernos de Educação no 9, maio 1999. CNTE. 